\title{
MÉTODOS DE EXTRAÇÃO E LIMPEZA DE SEMENTES DE ARAÇÁ-BOI (Eugenia stipitata)
}

\author{
Daniel Felipe de O. GENTIL', Sidney Alberto do N. FERREIRA²
}

RESUMO - O araçá-boi (Eugenia stipitata McVaugh, Myrtaceae), espécic de origem amazónica, possui frutos de aroma e sabor agradáveis, com alto rendimento $\mathrm{em}$ polpa. O presente trabalho objetivou avaliar a qualidade fisica e fisiológica das sementes após extrações manual e mecảnica, limpeza por fricção com diferentes materiais (areia, serragem, areia+serragem, cal hidratada, em peneira e sem friç̧ão) e limpeza por fermentação natural (com e sem substituição diária da água, por $0,1,2,3,4$ e 7 dias). Com o método mecânico obteve-se a maior quantidade de polpa (78\% do peso e $81 \%$ do volume dos frutos). A fricção com cal hidratada proporcionou as maiores percentagem $(98 \%)$ e velocidade de emergência $(0,989)$. Na fermentação natural, a manutenção da mesma água por mais de 1 dia afetou negativamente a qualidade fisiológica das sementes.

Palavras-chave: beneficiamento, despolpamento, fricção, fermentação.

\section{Methods of Extraction and Cleaning of Seeds of Araçá-boi (Eugenia stipitata)}

\begin{abstract}
The araçá-boi (Eugenia stipitata McVaugh, Myrtaceae) an Amazonian species, has fruits with agreeable aroma and flavour, and high pulp yield. This study evaluated physical and physiological seed qualities after hand and mechanical extraction, cleaning by friction with different materials (sand, sawdust, sand+sawdust, hydrated lime, on a sieve, and without friction) and cleaning by natural fermentation (with and without change of water every $0,1,2,3,4$ e 7 days). The mechanical method allowed extraction of the largest quantity of pulp $(78 \%$ of weight and $81 \%$ of fruit volume). Friction with hydrated lime gave the highest percentage (98 $\%)$ and germination speed $(0,989)$. Under natural fermentation, keeping the same water for more than one day negatively affected the physiological quality of the seeds.
\end{abstract}

Key-words: processing, pulping, friction, fermentation.

\section{INTRODUÇÃO}

Espécie de origem amazônica, pertencente à familia Myrtaceae, o araçá-boi (Eugenia stipitata McVaugh) possui frutos de aroma e sabor agradáveis, com alto rendimento em polpa, sendo geralmente consumida na forma de refresco, sorvete, geléia e licor. O fruto é uma baga globosa-depressa ou esférica, com 4,3-9,9 cm de diâmetro, 4,0-9,7 cm de comprimento e 50-585 $\mathrm{g}$ de peso, podendo chegar a $800 \mathrm{~g}$; o epicarpo é delgado, com pubescência fina e coloração verde-escura, que se torna amarelo-pálida ou alaranjada quando maduro; a polpa é mole-sucosa, amarelada, aromática e de sabor agridoce; as sementes são em número de 3 a 22 por fruto (Cavalcante, 1991; Chávez \& Clement, 1984; Ferreira, 1992).

Tradicionalmente, a extração das sementes é feita manualmente (Pinedo, 1981). A utilização de despolpadeira nesse processo vem sendo adotada há poucos anos, no Instituto Nacional de Pesquisas da Amazônia, em Manaus, AM. Entretanto, não foram estudados seus efeitos na qualidade das sementes, já que as características dos

\footnotetext{
' Doutorando em Fitotecnia, ESALQ-USP. Av. Pádua Dias, 11 - Cx. Postal 9 - 13418-900 Piracicaba, SP, Brasil.

${ }_{2}^{2}$ Pesquisador, INPA-CPCA, Cx. Postal 478, 69011-970, Manaus, AM. Brasil.
} 
componentes do equipamento e/ou sua regulagem deficiente podem acarretar danos às mesmas (Silva, 1983), como foram observados em sementes de Theobroma grandiflorum por Gato (1992).

As sementes de E. stipitata extraídas manualmente apresentam muitos residuos de polpa e tecido placentário aderidos ao tegumento. Por isso, são geralmente submetidas à friç̧ão com areia ou areia e serragem (1:1/v:v) e posterior lavagem (Pinedo, 1981). As sementes extraídas pela despolpadeira, entretanto, possuem menos residuos de polpa e tecido placentário, mas ficam misturadas com as cascas (epicarpo) dos frutos. A limpeza neste caso consiste na separação manual e na lavagem em água corrente, com pressão sobre peneira. Na limpeza de sementes de outras espécies vem sendo recomendado o emprego de substâncias químicas, como a cal hidratada em Passiflora edulis $\mathrm{f}$. flavicarpa (Manica, 1981) e Carica papaya (Manica, 1982), e da fermentação natural em Coffea arabica (Dias \& Barros, 1993).

O presente trabalho teve como objetivo avaliar a qualidade física e fisiológica das sementes de Eugenia stipitata após extração e limpeza por diferentes métodos.

\section{MATERIAL E MÉTODOS}

Três experimentos foram conduzidos nas dependências do Instituto Nacional de Pesquisas da Amazônia e da Universidade do
Amazonas, em Manaus, AM, no período de janeiro de 1996 a janeiro de 1997.

No primeiro experimento, frutos maduros e com valores médios de diâmetro de $7,06 \mathrm{~cm}$ (desvio padrão = $1,31 \mathrm{~cm}$ ) foram colhidos, lavados e separados em 10 repetições de 20 unidades cada, nas quais foram determinados o volume e o peso inicial. Os frutos foram submetidos à extração manual e mecânica, com verificação do peso total e do volume total da massa de sementes obtida por repetição em cada método. Na extração mecânica foi empregada a despolpadeira Lombard Super, modelo 9 , com peneira de $1,5 \mathrm{~mm}$ de malha, acoplada a um motor de indução trifásico Weg, de $1 \mathrm{cv}$ e $830 \mathrm{rpm}$. O tempo requerido para extração, a cada $1 \mathrm{~kg}$ de frutos, foi de 55 e 60 segundos, respectivamente, pelo método manual e mecânico, determinado em ensaio preliminar. $\mathrm{O}$ delineamento empregado foi o inteiramente casualizado, com dois tratamentos e cinco repetições cada, sendo as médias comparadas pelo teste de Tukey ao nível de $5 \%$ de probabilidade.

No segundo experimento, sementes extraídas manualmente foram submetidas à fricção manual com areia peneirada $(1: 1 / \mathrm{v}: \mathrm{v})$, serragem peneirada $(1: 1 / \mathrm{v}: \mathrm{v})$, areia+serragem peneiradas $(1: 1(1 / 2$ areia $+1 / 2$ serragem)/v:v), cal hidratada $(5,5: 1 /$ $v: v)$ e em peneira. Sementes extraidas em despolpadeira foram separadas manualmente dos restos de casca e 
tecido placentário (sem fricção). Posteriormente, as sementes foram lavadas em água corrente, com pressão sobre peneira.

Após a limpeza, as sementes foram semeadas em caixas de madeira, contendo serragem parcialmente decomposta peneirada, alocadas em viveiro coberto com telha de fibra transparente. A irrigação foi realizada sempre que necessário, de modo a manter o substrato úmido.

A avaliação da emergência de plântulas foi feita a partir do aparecimento da parte aérea acima do nivel do substrato, duas vezes por semana, até quando não foi evidenciada nenhuma emergência por um período de 15 dias. Os dados de emergência foram transformados em arco seno raiz quadrada da proporção, conforme Centeno (1990). O vigor foi avaliado através do indice de velocidade de emergência (IVE), pela fórmula proposta por Maguire (1962). Foi empregado o delineamento inteiramente casualizado, tendo seis tratamentos com quatro repetições de 25 sementes cada, sendo as médias comparadas pelo teste de Tukey ao nivel de $5 \%$ de probabilidade.

No terceiro experimento, sementes extraidas manualmente de frutos maduros foram separadas em dois lotes de sete litros e colocadas em baldes plásticos com água limpa (1:2/ $\mathrm{v}: \mathrm{v})$. A substituição diária da água foi feita num dos baldes, enquanto no outro foi realizada diariamente apenas uma agitação com auxílio de um bastão de madeira. Os baldes ficaram em ambiente com temperatura mínima (média) de $27^{\circ} \mathrm{C}$ e máxima (média) de $31^{\circ} \mathrm{C}$.

Aos $0,1,2,3,4$ e 7 dias de fermentação natural foi retirada uma amostra de $500 \mathrm{ml}$ de sementes de cada balde e submetida à lavagem em água corrente, com pressão sobre peneira. Em seguida, quatro repetições de 25 sementes cada por tratamento (tipo e tempo de fermentação), foram semeadas em bandejas plásticas, tendo como substrato serragem parcialmente decomposta peneirada, sob viveiro com $50 \%$ de luminosidade. Foi adicionado um tratamento testemunha, em que as sementes não haviam recebido nenhum tipo de fermentação e foram semeadas logo após a lavagem. A irrigação foi realizada sempre que necessário, de modo a manter o substrato úmido.

A avaliação da emergência de plântulas e a determinação do IVE, bem como a transformação de dados, foram realizados do mesmo modo que o experimento anterior. Foi empregado o delineamento inteiramente casualizado, em esquema fatorial $2 \times 5$, mais o tratamento adicional (testemunha), com quatro repetições de 25 sementes cada. As médias foram comparadas pelo teste de Tukey ao nivel de $5 \%$ de probabilidade.

\section{RESULTADOS E DISCUSSÃO} extração.

Experimento 1: métodos de

$\mathrm{O}$ requerimento de tempo na 
extração das sementes pelos métodos empregados foi praticamente o mesmo. Apesar de haver diferença significativa entre os métodos, pode ser verifícado que os frutos de Eugenia stipitata apresentam alto rendimento em polpa (Tabela 1), confirmando os resultados de Pinedo et al. (1981), Andrade et al. (1989) e Ferreira (1992).

Considerando o rendimento em polpa e a quantidade de resíduos presentes na massa de sementes após sementes quanto a industrialização da polpa, o que justificaria a aquisição da despolpadeira.

Experimento 2: limpeza por fricção.

O tratamento "sem friç̧ão" foi o que necessitou de mais tempo (Tab. 2), por causa da separação das sementes que se encontravam misturadas aos restos de casca e tecido placentário. $\mathrm{O}$ tratamento "fricção com cal hidratada" foi o menos trabalhoso, pois o produto químico degradou rapidamente os

Tabela 1. Rendimento em polpa e quantidade de resíduos presentes na massa de sementes de Eugenia stipitata obtida por diferentes métodos de extração.

\begin{tabular}{lcccc}
\hline \multirow{2}{*}{ Tratamento } & \multicolumn{2}{c}{ Rendimento em polpa } & \multicolumn{2}{c}{ Quantidade de resíduos $^{1}$} \\
\cline { 2 - 5 } & $\%$ peso & $\%$ volume & $\%$ peso & $\%$ volume \\
\hline Extração manual & $66,1 \mathrm{~b}$ & $68,7 \mathrm{~b}$ & $80,4 \mathrm{a}$ & $80,8 \mathrm{a}$ \\
Extração mecânica & $78,1 \mathrm{a}$ & $81,2 \mathrm{a}$ & $68,4 \mathrm{~b}$ & $61,5 \mathrm{~b}$ \\
CV (\%) & 3,1 & 2,9 & 2,6 & 2,5 \\
\hline $\begin{array}{l}\text { 1- As médias seguidas de mesma letra năo diferem entre si pelo teste de Tukey, ao nivel } \\
\text { de 5\% de probabilidade. }\end{array}$
\end{tabular}

a extração (Tab. 1), pode ser constatado que o método manual foi menos eficiente que o mecânico. Assim, é recomendável que aquele seja empregado nos casos em que haja pouca quantidade de frutos e/ou não se pretenda aproveitar a polpa para a comercialização.

$\mathrm{O}$ método mecânico extraiu a maior quantidade de polpa e, por conseguinte, deixou menos resíduos na massa de sementes. Desse modo, poderá ser adotado para grandes quantidades de frutos, quando se pretenda tanto o aproveitamento das resíduos aderidos ao tegumento das sementes.

O tratamento "fricção com cal hidratada" proporcionou uma remoção mais completa dos resíduos de polpa e tecido placentário que os demais

Tabela 2. Tempo médio requerido na limpeza, incluindo a lavagem, de $1 \mathrm{~kg}$ de sementes de Eugenia stipitata.

\begin{tabular}{lc}
\hline \multicolumn{1}{c}{ TRATAMENTO } & TEMPO \\
\hline Sem fricção & $16^{\prime} 10^{\prime \prime}$ \\
Fricção com areia & $10^{\prime} 30^{\prime \prime}$ \\
Fricção com serragem & $07^{\prime} 51^{\prime \prime}$ \\
Fricção em peneira & $07^{\prime} 31^{\prime \prime}$ \\
Fricção com areia + serragem & $07^{\prime} 08^{\prime \prime}$ \\
Fricção com cal hidratada & $05^{\prime} 07^{\prime \prime}$ \\
\hline
\end{tabular}


tratamentos. As sementes submetidas à "fricção com areia" foram as que apresentaram mais resíduos após a limpeza.

A percentagem de emergência apresentou diferença significativa apenas entre os tratamentos "friç̧ão com cal hidratada" e "fricção com areia", sendo que o maior valor foi obtido no primeiro tratamento (Tab. 3). Tais resultados indicam a influência negativa dos resíduos sobre a emergência e que, provavelmente, estão relacionadas com a eficiência do processo de limpeza das sementes. Os destas sementes. O despolpamento mecânico (sem friç̧ão) não provocou injúrias visíveis nas sementes. Contudo, quando for necessário armazenar as sementes, é recomendável adotar os métodos de extração manual e de limpeza por "fricção com serragem" ou "areia+serragem", até que seja verificado se, após a aplicação dos tratamentos "fricção com cal hidratada", "em peneira" e "sem fricçâo" (despolpamento mecânico), podem ocorrer efeitos latentes, os quais tornam-se aparentes somente

Tabela 3. Emergência e índice de velocidade de emergência (IVE) de plântulas, oriundas de sementes de Eugenia stipitata submetidas a diferentes métodos de limpeza'.

\begin{tabular}{lcc}
\hline \multicolumn{1}{c}{ Tratamento $^{2}$} & Emergência (\%) & NE \\
\hline Friç̧ão com cal hidratada & $98 \mathrm{a}$ & $0,989 \mathrm{a}$ \\
Friç̧ão com serragem & $96 \mathrm{ab}$ & $0,849 \mathrm{ab}$ \\
Fricção em peneira & $92 \mathrm{ab}$ & $0,804 \mathrm{bc}$ \\
Fricção com areia+serragem & $92 \mathrm{ab}$ & $0,749 \mathrm{bc}$ \\
Sem friç̧ão & $91 \mathrm{ab}$ & $0,781 \mathrm{bc}$ \\
Fricção com areia & $89 \mathrm{~b}$ & $0,657 \mathrm{c}$ \\
CV (\%) & 7,0 & 10,1 \\
\hline
\end{tabular}

1-As médias seguidas de mesma letra não diferem entre si pelo teste de Tukey, ao nível de $5 \%$ de probabilidade.

2 - No tratamento "Sem friç̧ăo" as sementes foram extraídas pelo método mecânico, sendo nos demais pelo manual.

dados de velocidade de emergência de plântulas confirmaram a melhor resposta das sementes tratadas com "cal hidratada" (Tab. 3).

Apesar de ter sido observado o escurecimento do tegumento, nas sementes submetidas à "fricção com cal hidratada", e a ocorrência de pequenas escarificações, provocadas pela "fricção em peneira", não foi constatado nenhum efeito imediato de danos sobre a qualidade fisiológica após períodos variáveis de armazenamento (Popinigis, 1977). Da mesma forma, deve-se evitar armazenar as sementes limpas por "fricção com areia", pois os resíduos que ainda permanecem com as sementes após o tratamento podem servir de substrato para microrganismos.

Experimento 3: limpeza por fermentação.

A fermentação natural facilitou 
a remoção dos residuos aderidos ao tegumento das sementes durante a lavagem, principalmente naquelas em que ocorreu a "substituição diária da água".

A emergência de plântulas apresentou efeito de interação significativo entre os fatores "substituição diária da água" e "dias de fermentação" (Tab. 4). Essa variável foi significativamente superior nas sementes submetidas a emergência foi obtido com " 1 dia de exposição". A fermentação por mais de 1 dia, sem a substituição da água, provocou uma redução na taxa de emergência de plântulas.

As médias do indice de velocidade de emergência de plântulas apresentaram diferença significativa apenas em relação a "substituição diária da água" (Tabela 5). A "fermentação sem substituição diária da água" afetou negativamente o vigor

Tabela 4. Emergência de plântulas oriundas de sementes de Eugenia stipitata submetidas a limpeza por fermentação natural, com e sem substituição diária da água em diferentes periodos'.

\begin{tabular}{|c|c|c|c|}
\hline \multirow{2}{*}{$\begin{array}{l}\text { Dias de } \\
\text { fermentação }\end{array}$} & \multicolumn{2}{|c|}{ Substituição diária da água } & \multirow[t]{2}{*}{ Média } \\
\hline & com & sem & \\
\hline 1 & 96 a $A$ & $98 \mathrm{a} \quad \mathrm{A}$ & $97 \mathrm{a}$ \\
\hline 2 & 99 a $A$ & $86 \mathrm{~b} \quad \mathrm{~B}$ & $92 a b$ \\
\hline 3 & 94 a $A$ & $93 \mathrm{ab} A$ & $94 a b$ \\
\hline 4 & 95 a $\mathrm{A}$ & $88 \mathrm{~b} \quad \mathrm{~A}$ & $92 \mathrm{ab}$ \\
\hline 7 & 92 a $A$ & $88 \mathrm{~b}$ & $90 \mathrm{~b}$ \\
\hline Média & $95 \mathrm{~A}$ & 91 & - \\
\hline $\operatorname{CV}(\%)=9,5$ & & Testemunha & 80 \\
\hline
\end{tabular}

1 - As médias seguidas de mesma letra minúscula nas colunas e de mesma letra maiúscula nas linhas nāo diferem entre si pelo teste de Tukey, ao nivel de $5 \%$ de probabilidade.

"fermentação com substituição diária da água". Quanto aos períodos de fermentação, dentro desse tratamento, os resultados foram semelhantes, indicando que não houveram prejuízos à qualidade fisiológica das sementes. Contudo, quando a fermentação se deu "sem substituição diária da água", o melhor resultado de taxa de das sementes.

Conforme Pinedo (1981), uma forma de conservar as sementes de Eugenia stipitata é mantê-las em água por até 60 dias, com substituição da água a cada 2 dias. Apesar de não ser um estudo de conservação de sementes, os dados obtidos neste experimento indicaram que as 
Tabela 5. Índice de velocidade de emergência de plântulas oriundas de sementes de Eugenia stipitata submetidas a limpeza por fermentação natural, com e sem substituição diária da água, em diferentes periodos'.

\begin{tabular}{|c|c|c|c|}
\hline \multirow{2}{*}{$\begin{array}{c}\text { Dias de } \\
\text { Fermentação }\end{array}$} & \multicolumn{2}{|c|}{ Substituição diária da água } & \multirow[t]{2}{*}{ Média } \\
\hline & com & sem & \\
\hline 1 & 0,836 & 0,739 & $0,787 \mathrm{a}$ \\
\hline 2 & 0,814 & 0,729 & $0,771 \mathrm{a}$ \\
\hline 3 & 0,806 & 0,795 & $0,801 \mathrm{a}$ \\
\hline 4 & 0,852 & 0,829 & $0,841 \mathrm{a}$ \\
\hline 7 & 0,796 & 0,773 & $0,785 \mathrm{a}$ \\
\hline Média & $0,821 \mathrm{~A}$ & $0,773 \mathrm{~B}$ & - \\
\hline $\operatorname{CV}(\%)=9,4$ & & Testemunha & 0,528 \\
\hline
\end{tabular}

sementes podem ficar imersas em água por até 7 dias, com substituição diária da água, sem que ocorram prejuizos a sua qualidade fisiológica. Assim, tal procedimento poderá ser adotado nos casos em que houver a necessidade do adiamento da semeadura por um curto periodo de tempo.

\section{CONCLUSÕES}

O método mecânico proporcionou uma extração mais eficiente, deixando menos resíduos na massa de sementes.

O tratamento "fricção com cal hidratada" promoveu uma remoção mais completa dos residuos de polpa e tecido placentário, aderidos ao tegumento das sementes, que os demais tratamentos. A qualidade fisiológica das sementes não foi prejudicada pela ação da cal hidratada.

A fermentação natural facilitou a remoção dos residuos, aderidos ao tegumento das sementes, durante a lavagem. Porém, a manutenção das sementes no mesmo meio de fermentação por mais de 1 dia afetou negativamente sua qualidade fisiológica.

\section{AGRADECIMENTOS}

Agradecemos aos Srs. Josias de Souza Queiroz (CPCA-INPA) e Jocélio Silva de Castro (FCA-UA) pelo apoio prestado no desenvolvimento deste trabalho. 


\section{Bibliografia citada}

Andrade, J.S.; Aragão, C.G.; Chaar, J.S.; Leão, I.M.S. 1989. Caracterização do araçá-boi (Eugenia stipitata sub. esp. sororia McVaugh). In: Congresso Brasileiro de Ciência e Tecnologia de Alimentos, 12, Rio de Janeiro, 1989. Anais... SBCTA, Rio de Janeiro. p.87.

Cavalcante, P.B. 1991. Frutas comestiveis da Amazônia. 5, ed. Edições CEJUP/Museu Paraense Emilio Goeldi, Belém. 279p.

Chávez F., W.B.; Clement, C.R. 1984. Considerações sobre o araçá-boi (Eugenia stipitata McVaugh, Myrtaceae) na Amazônia Brasileira. In: Congresso Brasileiro de Fruticultura, 7, Florianópolis, SBF, 1984. Anais... SBF, Florianópolis. p.167-177.

Centeno, A.J. 1990. Curso de estatistica aplicada à biologia. Coleção Didática, 3 . Centro Editorial e Gráfico/UFG, Goiânia. $188 \mathrm{p}$.

Dias, M.C.L.; Barros, A.S.R, 1993. Avaliação de métodos para remoção da mucilagem de sementes de café (Coffea arabica L.). Revista Brasileira de Sementes, 15(2):191-195.

Ferreira, S.A.N. 1992, Biometria de frutos de araçá-boi (Eugenia stipitata McVaugh). Acta Amazonica, 22(3):295-302.

Gato, A.M.G. 1992. Conservação de sementes de Theobroma grandiflorum (Willd. ex Spreng.) Schum - Sterculiaceae. Dissertação de Mestrado. INPA/FUA, Manaus. 110p.
Maguire, J.D, 1962. Speed of germination: aid in selection and evaluation for seedling emergence and vigour. Crop Science, 2(2):176-177.

Manica, I. 1981. Fruticultura tropical: $I$. Maracujá. Ed. Agronômica Ceres, São Paulo, 160p.

Manica, I. 1982. Fruticultura tropical: 3. Mamão. Ed. Agronômica Ceres, São Paulo. 276p.

Pinedo P., M.H. 1981. Cultivo del araza. Divulgacion, 01. INIPA/CIPA XVI, Iquitos. $15 \mathrm{p}$.

Pinedo P., M.H,; Ramirez N., F,; Blasco L., M. 1981. Notas preliminares sobre el araza (Eugenia stipitata), frutal nativo de la Amazonia peruana. Publ. Misc., 229. MAA-INIA/IICA, Lima. 58p.

Popinigis, F. 1977. Fisiologia da semente. AGIPLAN, Brasília. 289p.

Silva, R.F. 1983. Extração de sementes de frutos carnosos. In: Carvalho, N.M.; Nakagawa, J. (coord.) Sementes: ciência, tecnologia e produção. 2. ed. rev. Fundação Cargill, Campinas. p.379-404. 